\title{
How does biodiesel compare to other renewable diesel fuels?
}

Abbreviations: $\mathrm{GHG}$, greenhouse gas; $\mathrm{CO}_{2}$, carbon dioxide; $\mathrm{CO}$, carbon monoxide; NOx, nitrous oxides; HC, hydrocarbons; PM, particulate matter; HVO, hydrogenated vegetable oil; GtL, Gas-toliquid; BtL, Biomass-to-Liquid; B20, biodiesel; ULSD, ultra -low sulfur diesel

\section{Opinion}

Focusing on heavy modes of transport such as trucks, trains, boats and barges, diesel fuel currently provides the majority of the "kick" that is needed to meet the demands of the modern standard of living in the developed world and the increasing demand of energy in the developing world.

Recently, diesel is facing a "backlash" after Volkswagen's "dieselgate", which revealed the intentional manipulation of nitrogen oxides (NOx) in official engine test results. The scandal hit at a time when air pollution was becoming an increasingly political issue for cities around the world. Some cities, including Paris, Mexico City and Madrid, have even announced bans for diesel vehicles from 2019 onwards.

As air and sea traffic grow and as the developing world expands economically, the diesel engine will continue to play a key role in the transportation sector. Therefore, "defossilizing" this area of the transportation sector for the long-term will be necessary if the world's governments are to meet temperature reduction targets set by the Paris Climate Agreement

Although alternative, renewable fuels, also referred to as Biofuels, for diesel engines can be derived from a wide range of bio-based feedstock's, their methods of production, vehicle use and benefits are distinctly different from each other.

The purpose of this presentation is to provide a general overview of the renewable fuels available for the diesel engine in order to inform key decision makers and people who are just curious to learn more about the role alternative diesel fuels will play in the near future.

Included among the various alternative diesel fuel options that will be discussed are biodiesel (FAME), hydrogenated vegetable oil (HVO), Gas-to-Liquid (GtL) and Biomass-to-Liquid (BtL) fuels.

Whenever renewable fuels are discussed they should always be able to answer the following question..

a. Is it coherent as it claims to be?

b. Is it co-producible?

c. Is it compatible with the diesel engine?

d. How competitive is it with petrol-diesel?

The first section is addressed to how sustainable renewable diesel fuels are, or in other words, how coherent is the fuel? This breaks down into what feedstock the fuel is made from and the emissions it emits into the atmosphere when combusted. For all intents and purposes,

\author{
Volume 2 Issue 3 - 2018 \\ Michael D Eggleston \\ International Engineering Student, Pharmaceutical Chemical \\ Engineering, Germany
}

Correspondence: Michael D Eggleston, International Engineering Student, Pharmaceutical Chemical Engineering, International Development, Tel +4916 3373 0503, Email meggleston@my.uri.edu

Received: April 28, 20I8 | Published: May II, 2018

this presentation just focuses only on comparing the greenhouse gas (GHG) emissions of the fuels, primarily carbon dioxide $\left(\mathrm{CO}_{2}\right)$, carbon monoxide (CO), nitrous oxides (NOx), hydrocarbons ( $\mathrm{HC}$ ) and particulate matter (PM). On the surface FAME provides the majority of secondary GHG emission reductions, such as that in PM, CO and $\mathrm{HC}$. However, with conventional feedstock's, $\mathrm{CO}_{2}$ emissions of FAME remain below newly proposed legislation in the EU (Renewable Energy Directive - RED II) and also pose a serious risk to increase NOx emissions. On the other hand HVO and BtL provide significant $\mathrm{CO}_{2}$ reductions and $\mathrm{GtL}$ proves to be a suitable long-term substitute to FAME in regards to $\mathrm{HC}$ reductions, as long as it is accompanied with a particle filter to compensate for reduced PM reductions.

Moving towards the production of renewable diesel fuels, HVO is the only "drop-in" fuel to which can be manufactured with the same existing petrol-diesel infrastructure operating at similar conditions such as temperature and process chemistry (hydrodesulphurization). The processes of the other fuels take on other forms such as the exchange of alcohols (FAME), the synthesis of syngas (GtL) and the intense break down of hydrocarbons via pyrolysis (BtL).

Discussing whether these fuels are compatible with the diesel engine requires an understanding of the limitations and advantages these fuels propose. For example, in most cases there is a strict blending limit to about $20 \%$ for biodiesel (B20) to prevent increased NOx emissions, decreased torque and corrosion of engine parts such as gaskets. Biodiesel is not all that bad having superior lubricity and handeling (flash point) properties. Ultimately, if the aim is to reduced emissions such as sulfur, particulate matter etc (expect for NOx) it is best to have a higher level blend, such as B20, however if the aim is to increase lubricity in ultra -low sulfur diesel (ULSD), for example, then blends of 2-5\% (B2-B5) will suffice. In comparison to other renewable diesel fuels, biodiesel is outmatched by ignitability (cetane number), energy density (besides that of GtL) and its storage performance (oxidative stability).

Lastly, in reviewing how competitive biodiesel is in comparison to other developing and available renewable diesel fuels, understanding the results previously mentioned in terms of the short to long-term integration is key. Therefore I propose, that:

i. FAME from conventional feedstock's should only serve as an additive to improve lubricity, storage handling and decrease PM 
emissions in the short-term as Biological-GTL (FAME produced from syngas) develops

ii. HVO should serve as an immediate drop-fuel fuel with immediate $\mathrm{CO}_{2}$ reductions in the short to medium-term

iii. Immediate attention is needed to coordinate a decentralized collection of waste residues to make GtL/BtL cost competitive

iv. Conduct research into GtL/BtL co-blending for the long-term

Michael Eggleston is an aspiring policymaker studying interdisciplinary \& intercultural communication with the University of Rhode Island's International Engineering Program. He is spending a semester abroad at the Technische Universität Darmstadt in Darmstadt, Germany and will be reporting on and representing Advanced Biofuels USA at international conferences surrounding Europe's energy transition.

\section{Acknowledgements}

None.

\section{Conflict of interest}

Author declares that there is no conflict of interest. 